\title{
Impact of MOOC in Teachers' Education Through Swayam Platform - In Indian Context
}

\author{
K. James Mathai \\ National Institute of Technical Teachers' Training \& Research (NITTTR) \\ India
}

\begin{abstract}
Massive Open Online Learning Course (MOOC) is a new phenomenon in India providing opportunities for life-long learning. Here learner can choose from hundreds of courses taught at the university / college / school level. The transfer of credit earned by taking these courses into their academic record of students and for teachers for career advancement schemes makes it more encouraging to the learners. The professors of centrally funded institutions like NITTTRs, IITs, IIMs, central universities etc. are engaged in offering Massive Open Online Courses (MOOCs) to citizens of India through SWAYAM - an innovative platform for learners of Higher Education and Teachers. This platform 'Study Webs of Active Learning for Young Aspiring Minds programme' (SWAYAM) is developed by Ministry of Human Resource Development, Government of India along with the regulatory bodies - All India Council of Technical Education and University Grants Commission (UGC) of India. The author of this paper- as developer and coordinator, critically examines a course offered on 'ICT in Teaching and Learning' in the context of Indian higher/teacher education offered through this SWAYAM platform. This paper discusses the emerging views of Constructivist and Connectivist Learner-centered theories of learning, design framework, the impact of the MOOC on 'ICT in Teaching and Learning' offered for aspiring and in-service teachers of India and the challenges faced by the author in which 8612 nos. of learners had enrolled.
\end{abstract}

\section{Introduction}

SWAYAM seeks to bridge the digital divide for students who have hitherto remained untouched by the digital revolution and have not been able to join the mainstream of the knowledge economy. Designing a Massive Open Online Course (MOOC) is in constantly- an evolving form of digital outreach, combining elements of education and public engagement [1]. MOOC is a Massive or large-scale digital course designed to engage with a large number of in-service and aspiring teachers/ academia desiring to acquire a career-related skill-set and/or exploring the new pursuit of knowledge of interest. It is a confluence of education (i.e. teaching and learning) and learner's engagement. MOOC designers use various models; some use Analysis, Design, Development, and Implementation (ADDIE) [6][7] Model of instructional design. Other Models include Dick \& Carey and Kemp Instructional System Design (ISD) models etc.

Selection of Instructional Design System (IDS) and theories of learning plays an important role in the design of instructional systems. Theories such as behaviorism, constructivism, connnectivism or social learning and cognitivism help to shape and define the outcome of instructional materials too. In MOOCs; theories of Constructivism and Connectivism plays an important role as discussed below.

\section{The Emerging Views of Constructivist and Connectivist Learner centred Learning Theories}

Today, the teaching profession is evolving due to the emerging information and communication technologies. This has caused a shift in emphasis from teacher-centred lecture-based instruction to learnercentred interactive learning environments. At the same time, this shift is due to the change from conventional to emerging views of the learning process based on the Constructivist and Connectivist theories of learning. Constructivism suggests that the learner will learn better when he/she construct his own knowledge. Connectivism or distributed learning theory of teaching and learning [5] suggests that knowledge is not only located in textbooks or teacher head in the classroom but knowledge is distributed among different learners or experts and artifacts situated globally. Therefore, there is a need for active participation of learner on the network in the teaching and learning processes. This would need a paradigm shift from teaching to a learning environment which could be created through Technology Enabled Learning (TEL). It will make learning more interactive, flexible and engaging. 
Jo-Ann Boydston mentions, about the later works of educationist John Dewey [3]; in his book "Experience and Education, Freedom and Culture, Theory of Valuation, and Essay". He quotes "There is, I think, no point in the philosophy of Progressive education which is sounder than its emphasis upon the importance of the participation of the learner in the formation of the purposes which direct his activities in the learning process, just as there is no defect in conventional education greater than its failure to secure the active cooperation of pupils in construction of the purposes involved in the studying" (Page 43). Based on the above (John Dewey's) view of "active participation of learner" and on the basis of three decades of research in human learning; the Constructivist and Connectivist psychologist has brought about a new paradigm of the teachinglearning process. This is different, in contrast to conventional teaching and learning. The learning theories are called as 'Constructivism' and 'Connectivism'.

The Constructivism and Connectivism theories are often characterized by the human six learning processes [2], [12].

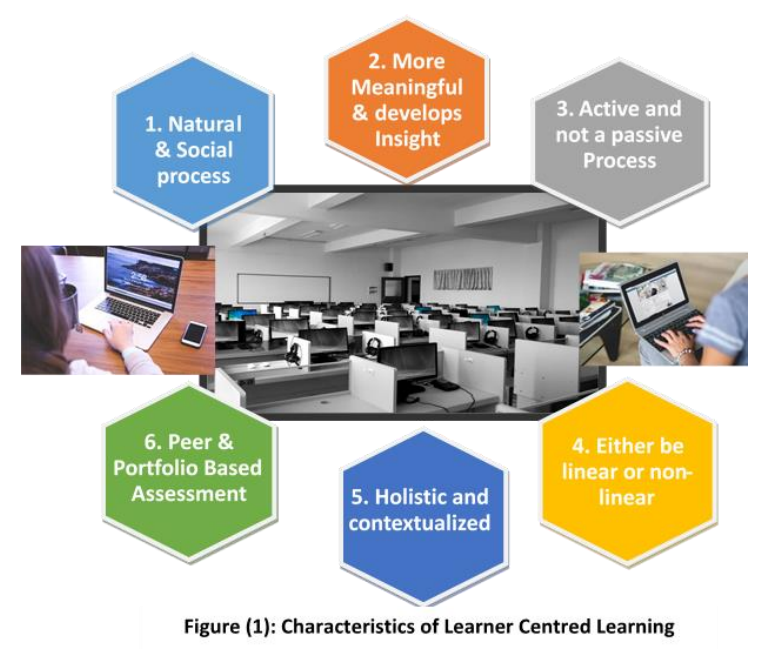

Figure 1. Characteristice of Learner Centred Learning

The above six characteristics of learner-centred learning depicted in figure (1) can be understood as follows.

According to the emerging views, learning is a natural process of the human brain. But not all learners learn the same way. Therefore, while designing the learning experiences, different learning styles must be considered by providing interesting and rich stimulating econtent for enhanced learning. The emerging Constructivist and Connectivist way of learning emphasizes on socially constructed knowledge. Sufficient opportunity must be provided by the teachers so that learners use interactive technology tools with peers for collaborative learning so that they reach "Zone of Proximal Development (ZPD)" [4]. This will enable more meaningful learning and will develop insight into the learners rather than promoting more of surface or rote learning just as in teacher-centred learning.

In this age of fast technological development in the industries, the design and implementation of technology-enabled learning like MOOCs will be the key to bring about educational reforms making learning active and possibly for a large number of technical teachers in India. The technology enables learning can make learning- linear or non-leaner, holistic and contextualized based on the learners' interest abilities and culture. TEL can make the leaner more empowered not only in learning processes but can also in assessment through peer and portfoliobased assessment.

\section{Design Framework of MOOC}

Based on the above-emerging views, first and foremost, the author has decided to identify a design framework as an Instructional Design System (IDS). The author as an instructional designer adapted ADDIE model for designing the massive open online course. Then it was decided to progressively implement the five design phases of ADDIE model as shown in Figure 2.

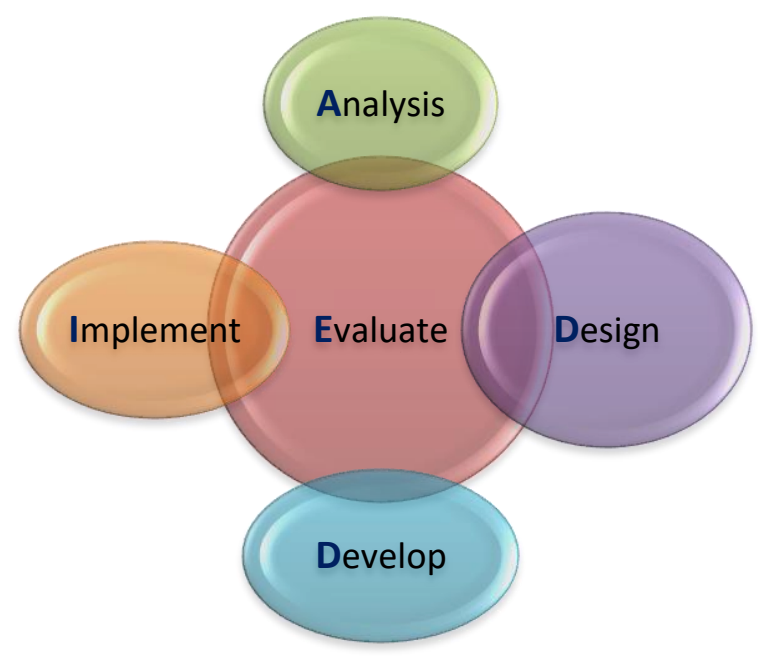

Figure 2. ADDIE Model of Instruction Design System

\subsection{Analysis}

As an initiative by Ministry of Human Resource Development (MHRD) and AICTE Govt. of India, teacher's education project was undertaken, taking into consideration the academic need of aspiring and in-service teachers/ academia of the country. It was decided to develop Massive Open Online Courses (MOOCs) as a joint project by four NITTTRs of the country for Technical Teachers' Education in India. 
In all, 50 MOOCs were identified of 50-Credits and of total 900-1000 hrs durations. NITTTR Bhopal took responsibility to develop and launch 13 nos. of courses out of which 'ICT in Teaching and Learning' was one among them. This course is a 'scheduled course' and was launched from $7^{\text {th }}$ Jan. to $1^{\text {st }}$ Feb.2019. A SWAYAM Academic Board (SAB) was responsible for guiding the National Coordinators (NC) and for laying down quality standards. NITTTR Chennai was identified as National Coordinator (NC) to coordinate and to timely launch the courses. It was decided that, after the successful completion of course activities and a proctored exam, the teachers would be awarded a certificate of achievement of 2 credits course. The course and contents posted in MOOCs is copyrighted to SWAYAM.

The author also identified co-faculty members to help in the development of learning materials and video tutorials and appointed Teaching Assistant (TA) to help in enhancing Learner - Instructor Interaction and assisting in the discussion forum on the SWAYAM course portal. The dashboard of the SWAYAM platform is as shown in Figure 3.

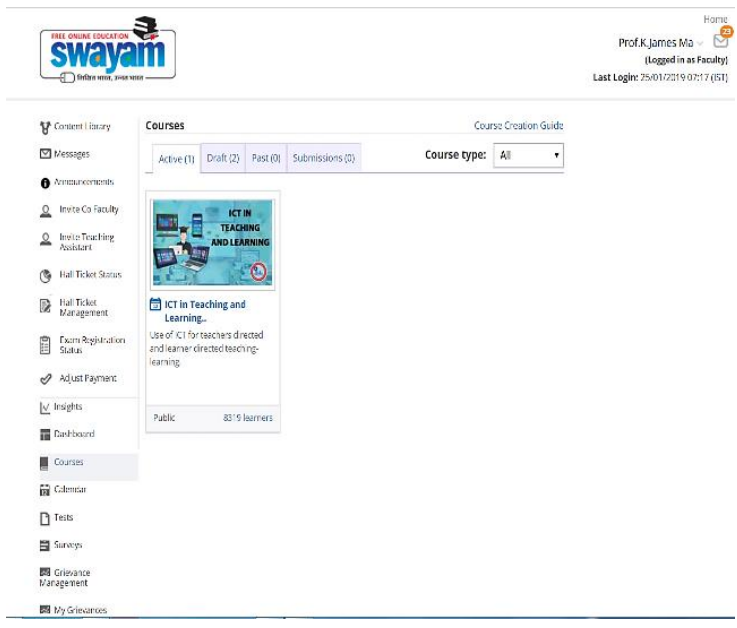

Figure 3. Dashboard of SWAYAM Platform

The basic objectives of the course were as follows:

i) Select an appropriate Information and

Communication Technology (ICT) in Teacher-

Directed Learning (TDL) and Learner Directed Learning (LDL) situation.

ii). Integrate an appropriate ICT pedagogy into the Teaching-Learning Process.

iii). Fortify the ethical- intellectual property rights /copyright handling, legal, security and Software related issues in using ICT.

\subsection{Designing}

The second most important phase was to detail, an outline of the course (course contents) to be taught and decide design aspects of each e-content material. As suggested by SWAYAM, the design of e-content materials of the course should be based on the 4quadrants approach as shown in Figure 4. The course outline had modules, units, and lessons. The learning material were developed as per 'Guidelines for developing Online Courses for SWAYAM' provided by MHRD [13].

The quadrant-1 (Q1) contain Audio or video lecture, the quadrant-2 (Q2) contain specially prepared self-learning material in a designed template that can be downloaded/printed. The quadrant-3 (Q3) was an online discussion forum for raising of doubts and clarifying them on a near real-time basis by the Course Coordinator or his team and quadrant-4 (Q4) contain Assessment; i.e. self-assessment tests through MCQs (quizzes), Assignments in form of Short Answer Questions, Long Answer Questions [13].

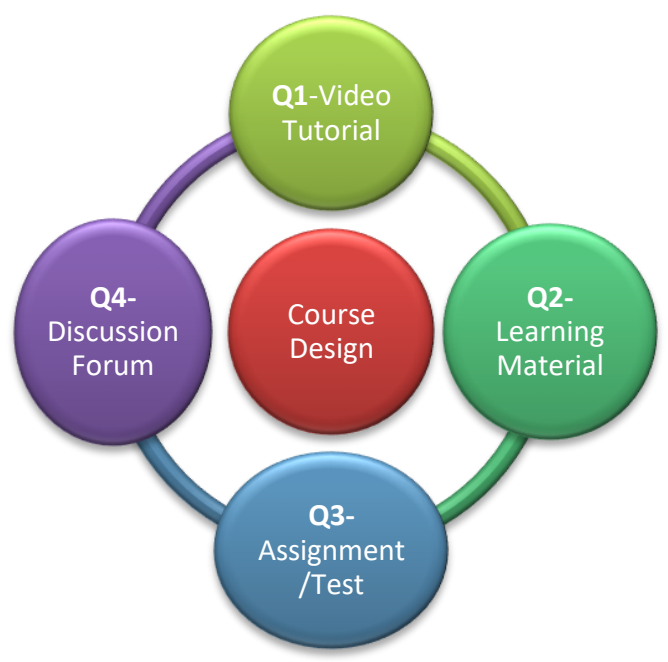

Figure 4. 4- Quadrant Design Approach

The author decided to design the 'Dashboard' for the learners with week wise e-content in order oflesson(s) as learning material, video tutorial(s) followed by Forum thread(s) with topics of discussion, test(s) and assignment(s) for each lesson of the course. The FAQs, the 'Announcements' to post messages from time-to-time for the learners; use of limited interactive tools such as discussion forum, email and messaging system for collaboration with learner to learner, learner to content and learner to the teacher were designed.

Steps to enrich the learning experience by using multi-media with available state of the art pedagogy/technology was taken up.

In order to develop quality learning material and ensure uniformity in the e-content development, the author designed template(s) for preparing learning materials and scripts for the video tutorial.

The Coding scheme for creating econtent files such as Video tutorial, learning materials in form of lessons, Graphics, Animation, PPT file and script file 
for every video tutorial(s) were essential for managing and uploading to the SWAYAM portal. So the naming convention of files were strictly followed as per the coding scheme is shown in Table 1.

Table 1. Coding Scheme to create an e-content file

\begin{tabular}{|c|l|c|c|c|c|c|}
\hline $\begin{array}{c}\text { Cour } \\
\text { se } \\
\text { Code }\end{array}$ & $\begin{array}{c}\text { File } \\
\text { type }\end{array}$ & MM & UU & LL & $\begin{array}{c}\text { Lesso } \\
\text { n } \\
\text { Nam } \\
\text { e }\end{array}$ & $\begin{array}{c}\text { Auth } \\
\text { or } \\
\text { Initia } \\
\text { l }\end{array}$ \\
\hline C06 & T- Text & Modu & Un & Less & $<8-20$ & KJM \\
& V- & le & it & on \\
char $>$ & \\
& Video & $(01-$ & $(01$ & $(01-$ & & \\
G- & nn) & - & nn) & & \\
& $\begin{array}{l}\text { Graphic } \\
\text { s }\end{array}$ & & nn) & & & \\
& & & & & \\
A- & & & & & \\
Animati & & & & & \\
\hline
\end{tabular}

(Example:

C06TM01U01L02EmergingTrendsofICTEnabledLe arningKJM

C06-Course Code, T-Text; 01: Module-01,01:Unit01,02:Lesson-02,

'EmergingTrendsofICTEnabledLearning': Lesson name, KJM-Author Initials)

It was also decided that the Learning Material to be developed as lesson(s) should be in the form of micro-content in the Course having around 3000 words for one hour. This is based on the assumption that an average student can read 3000 words in one hour. The video tutorial [8][9] would also be in the form of micro-content of 3-7 minutes duration. The concept of micro-content as a part of designing econtent was essential so that the learner using various mobile devices can have access to the e-content easily. Today, micro-content is the way of designing courseware. This is due to lack of standardization of technologies and limitation of mobile devices (such as smartphones, tablets, etc.) like storage space, bandwidth, screen size, resolution, etc.[10].The course on 'ICT in Teaching and Learning' was of 20 hrs duration, 1 hour per week and of total 5 weeks duration.

\subsection{Development}

The learning materials in the form of modules, units and lessons with MCQs as tests, assignments, topics of discussions were prepared by the team as shown in Figure 5. The High Definition (HD) video lectures were produced in the studio of our Institute as per the specification provided by SWAYAM guideline using various equipment's.

After the development of learning materials, complete course econtent and video lectures were passed through academic and technical review and subsequent approval from National Coordinator.

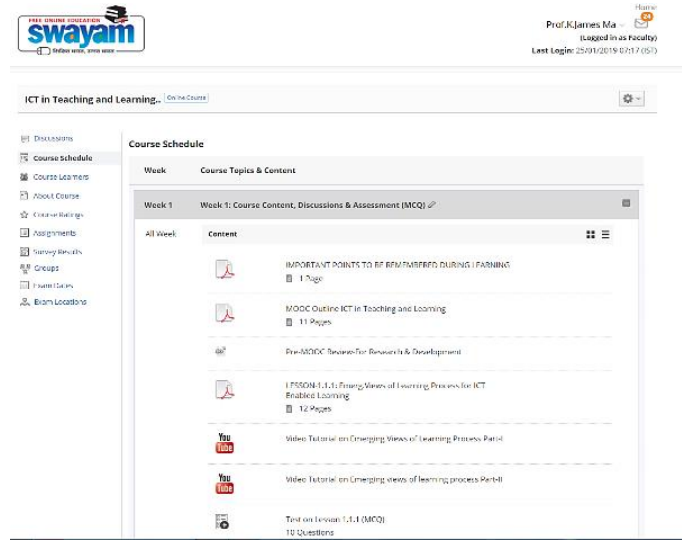

Figure 5. Course e-content on SWAYAM Platform

\subsection{Implementation}

The above learning materials developed were uploaded on the portal as shown in Figure 5. The authoring of these course materials was a challenging task due to the limitations in SWAYAM learning management system. The course on 'ICT in Teaching and Learning' is available at https://archive.swayam. gov.in/courses/4212-ict-in-teaching-and-learning.

Some of the other important steps taken during implementation of MOOC were as follow:

i). A web channel on Youtube was created by NITTTR Bhopal to upload all video tutorial of the MOOC. The econtent/lessons were uploaded on SWAYAM portal.

ii). The enrollment to the course started and in all 8612 learners got enrolled before the date of launching the course. Out of which 3267nos. $(37 \%)$ of the learners were 'active and in progress' and 5344 (62\%) learners did not access the course.

iii).About $54.47 \%$ of learners were male and $45.53 \%$ were female.

iv).An instrument to conduct pre-Survey and post-Survey was designed and administered. In all 2134 nos. active-learners attempted precourse test, out of which 1378 nos. mentioned that they have attended the course to enhance professional skills, 561 nos. mentioned for certification and 195nos. because of general interest. Out of 2134 nos. of active learners; on an average 674nos.learners attempted the scheduled tests and engaged in discussion forums provided time to time as part of assessment for certification.

v). According to the survey carried out, the learners were working in different field of work such as - administration (2.66\%), engineering and technology (18.26\%), science, Arts \& Commerce (35.46\%), teaching and research $(36.52 \%)$ and others $(7.09 \%)$. 
vi). On the question when asked learners about the 'option that best describes them'; they mentioned as - Faculty in Technical Institution/Technical University (21.5\%), Faculty working in UGC College/University (35.5\%), Professional educational Consultant (1.6\%), Teacher in educational institution $(24.07 \%)$, Retired faculty $(0.46 \%)$ and others about $17.01 \%$.

vii). Apart from creating forums for learning $\&$ discussions different forums-Lesson-wise to resolve the queries of learners was also created.

viii). A team of- co-cordinator, faculty member and Teaching Assistant were also enrolled in the course.

ix). The FAQs were set for clarifications on general queries and misconceptions.

$\mathrm{x})$. Time to time announcements was posted by the etutor, facilitated learning and organizing threads in the discussion forum.

xi).Provided timely feedback by the experts.

xii). Created 'Discuss with Tutor' discussion forum helped learner for posting queries to the tutors and also provided opportunities for peer- discussions as a community of learners.

xiii). According to a policy decision taken by SWAYAM and Academic Council; it was decided to conduct a proctored online examination of 3hrs duration with $100 \mathrm{MCQs}$ questions for certification. The exam was scheduled on $22^{\text {nd }}$ May 2019 and Percentage registered for the Exam is $2.59 \%$. The main reason for less participation is due to delay in conduct of exam, insufficient and late intimation to learners about the schedule of exams, etc.

\subsection{Evaluation}

In order to ensure the success of the course, continuous feedback and progress tracking was done. An instrument to conduct pre-test and post-test was designed and administered. In all, there were 10 multiple choice questions developed on the course content.

\section{Overall Rating of the course}

The overall course rating is given by 474 nos. of learners is 4.8 out of 5 as shown in Figure 6; that means 322nos. of leaners have rated it at 5 star.

The review with 1-star rating had the following feedback-

1. "Website and app both are not Mobile friendly. Neither e-content nor the test is accessible without Adobe flash plugin which is not supported by many mobile handsets. Unable to attend the course because of this problem."

2. "Unable to open on the smartphone and unable to open the test on the mobile."

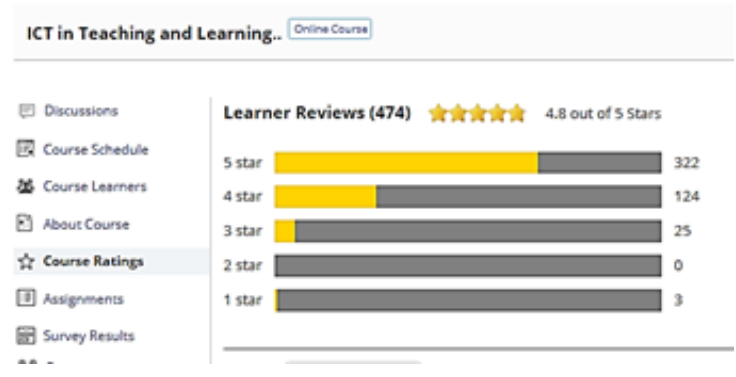

Figure 6. Overall Course Rating

\section{Effectiveness of Course}

The effectiveness of the massive open online course on 'ICT in Teaching and Learning' offered is evident by analyzing Graph 1 below.

Graph 1. Effectiveness of Teaching and Learning

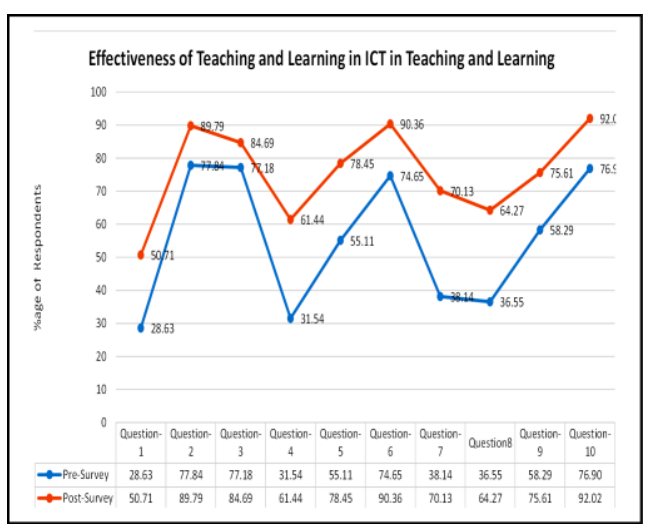

Based on the 10 MCQ's items designed on the course content to assess the effectiveness of the course, it can be observed that the learner has gained knowledge after completing the course.

\section{Overall Opinion about the MOOC}

Some of the Overall Opinion about the MOOC on 'ICT in Teaching and Learning' given by the leaners after its completion is as follows.

i) 'The course on 'ICT in teaching and learning' has been beautifully designed to enhance the teaching skills of teachers. This is an excellent course which has helped the teachers to facilitate learner-directed learning environment. All the lessons were configured logically, systematically and meaningfully. Textual and video lectures of this course were interesting, need-based and good. It has catered my learning 
needs and empowered me to deal with ICT tools and trained me to teach with the application of ICT tools.'

ii) 'Excellent. Course provided in-depth knowledge of the topic as well; motivating me to apply the techniques in my teaching methodology.'

iii) 'Excellent. The course is highly resourceful and very well designed to meet the requirements of the students in this digital world.'

iv) 'Excellent. It was my first experience on an interesting topic. Thanks team led by Dr. K. James Mathai and Swayam Team.'

v) 'It was a wonderful experience for me. After completion of the course, I came to know various methods of teaching pedagogy using ICT.'

vi) 'It's very beneficial to me. I got more knowledge about ICT. I am a college lecturer, so it's beneficial to me. Video tutorials and tests are very useful and interesting. Thanks to all faculties, for the wonderful class and all NITTTR team.'

vii) 'The course was very good, quizzes conducted after every section of the course helped to recollect the points.'

viii) 'The course designing and execution was good. etc.'

\section{Challenges faced in offering MOOC}

i). The scheduler of SWAYAM LMS for scheduling econtent, assignment, MCQ's etc. of the course is non-functional and therefore econtent became available before due time.

ii). After the user run the video tutorial that was uploaded on the YouTube Channel as per guideline provided by SWAYAM, all irrelevant video gets browsed on the site. On an educational website, this is beyond netiquette.

iii). There are absolutely no interactive tools including dedicated discussion forum available within the course-ware for reflecting on problems that can be scheduled soon after module/unit/lesson for encouraging the learner to interact on different issues of the topic. Discussion Forum is available outside the course where all other general discussions on 'issues of learner' takes place. Therefore, the actual use of discussion forum actually created for resolving queries by the instructor gets lost among other threads.

iv). All the etutors do not have the same privilege to launch uploaded econtent in the library. The econtents, tests, and assignments are not accessible to co-tutors $\&$ are available only to the etutor who has uploaded

v). The communication tools such as 'Announcement' and 'Discussion Board' are not accessible to etutors to communicate any important message(s) to learners after the due completion date of the course schedule.

vi). The weekly 'Tests' and 'Assignments' of LMS do not have the option to extend the due date.

vii). Access to any of the econtent on SWAYAM course requires Adobe plugin. It cannot be accessed by an internet browser alone. The lack of compatibility of adobe plugin on all the mobile devices creates difficulty in getting access to the econtent by mobile users.

viii). Website and app both are not Mobile users friendly.

\section{References}

[1] 'The Academic Association for Contemporary Studies (UACES) Designing a Massive Open Online Course (MOOC)', https://www.uaces.org/resources/ designing-amassive-open-online-course-mooc (Access date: 21 May 2019).

[2] Evgueni Khvilon et al, (2002), "Open and distance learning-trends, policies and strategies”, UNESCO.

[3] John Dewey, "The Later Works 1925-1953, John Dewey, Volume 13:1938-1939, Experience and Education, Freedom and Culture, Theory of Valuation, and Essays", Edited by Jo Ann Boydston, Southern Illinois University Press, Carbondale, 2008 ISBN-10 : 0-8093-2823-2

[4] Vygotsky, L.S. (1978), "Mind in Society”. Harvard University Press. Cambridge, MA.

[5] Joao Mattar(2010) Constructivism and Connectivism in Education Technology: Active, Situated, Authentic, Experiential, and Anchored Learning, Boise State University, 08/ 2010-version1.0

[6] J. Balanyk, 'Developing English For Academic Purposes MOOCS Using The ADDIE MODEL', 11th International Technology, Education and Development Conference, 6-8 March, 2017, Valencia, Spain.

[7] Norazah Nordin,Mohamed Amin Embi,Helmi Norman 'Towards Envisioning the Future of Learning in Malaysia: Development of a Malaysia MOOC Based on the Iterative ADDIE Instructional Design Framework', Conference on Envisioning the Future of Online Learning, 11 June 2016, pp 269-279

[8] Guo, P. J., Kim, J., \& Rubin, R. (2014). 'How video production affects student engagement: An empirical study of MOOC videos', In Proceedings of the first ACM conference on Learning at scale conference (pp. 4150).ACM.

[9] Adams, C., Yin, Y., Vargas Madriz, L. F., \& Mullen, C. S. (2014). 'A phenomenology of learning large: The tutorial sphere of xMOOC video lectures', Distance Education, 35(2), 202-216.

[10] K.J.Mathai, 'Mobile Learning in Higher Education through SWAYAM- Indian Context”, International 
Academic Conference on Teaching, Learning and Elearning (IAC-TLEl 2018), from 17-18th March 2018, Budapest, Hungary.

[11] James K Mathai, Mr.Ravi Limaye et al., 'Design and Evaluate Web based Courseware in Collaborative Learning Environment', World Congress on Education (WCE-2013), 2-4 September, 2013, London, U.K.

[12] Government of India Ministry of Human Resource Development, Department of Higher Education 'Guidelines for developing Online Courses for SWAYAM' (Revised) 1 st June 2017. 